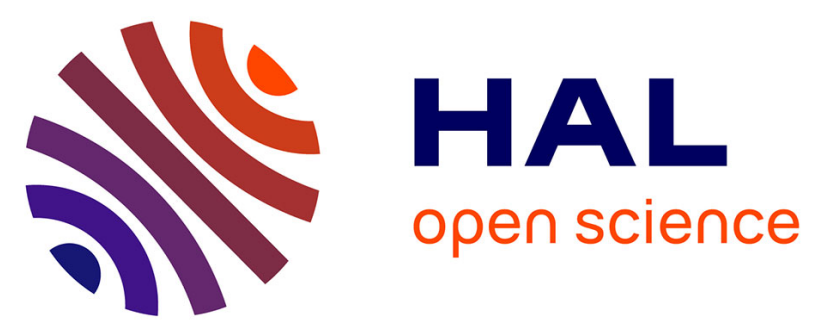

\title{
Analyzing the evolution of deterioration patterns: A first step of an image-based approach for comparing multitemporal data sets
}

Friederike Peteler, Eloi Gattet, Philippe Bromblet, Odile Guillon, Jean-Marc Vallet, Livio de Luca

\section{To cite this version:}

Friederike Peteler, Eloi Gattet, Philippe Bromblet, Odile Guillon, Jean-Marc Vallet, et al.. Analyzing the evolution of deterioration patterns: A first step of an image-based approach for comparing multitemporal data sets. Digital Heritage International Congress DH'15, Sep 2015, Granada, Spain. pp.113-116, 10.1109/DigitalHeritage.2015.7419465 . hal-02098401

\section{HAL Id: hal-02098401 https://hal.science/hal-02098401}

Submitted on 12 Apr 2019

HAL is a multi-disciplinary open access archive for the deposit and dissemination of scientific research documents, whether they are published or not. The documents may come from teaching and research institutions in France or abroad, or from public or private research centers.
L'archive ouverte pluridisciplinaire HAL, est destinée au dépôt et à la diffusion de documents scientifiques de niveau recherche, publiés ou non, émanant des établissements d'enseignement et de recherche français ou étrangers, des laboratoires publics ou privés. 


\title{
Analyzing the evolution of deterioration patterns:
}

\author{
A first step of an image-based approach for comparing multitemporal data sets
}

\author{
Friederike PETELER ${ }^{1}$, Eloi GATTET ${ }^{1}$, Philippe BROMBLET ${ }^{2}$, Odile GUILLON $^{2}$, Jean-Marc VALLET ${ }^{2} \&$ Livio DE LUCA $^{1}$ \\ ${ }^{1} \mathrm{UMR} 3495$ MAP CNRS/MCC \\ Marseille, France \\ \{friederike.peteler, eloi.gattet, livio.deluca\}@map.cnrs.fr
}

\begin{abstract}
When documenting and analyzing cultural heritage, the monument states can be described by multitemporal data sets, which however present a complication for the elaboration and examination process. This difficulty leads to the necessity to improve the analyze process in order to expand the documentation process and help experts to enrich and share information about the historical buildings. Therefore an approach of change measurement, which supports the chronical comprehension of a building by visualizing and quantifying the dimensional temporal effects was elaborated, where the analyze process of a multitemporal data set was based on the interpretation of depth map images. These maps were obtained by generating ortho images of an object that was created on purpose by setting up an experimentation to acquire a multitemporal data set.
\end{abstract}

This approach is the first step of a wider ongoing research about change detection processes on multitemporal data sets.

Index Terms-Change measurements, multitemporal data set, depth map, ortho image, evolution of deterioration patterns.

\section{INTRODUCTION}

In the field of preservation and valuation of cultural heritage, the monument states can be described by various sets of data like multitemporal data, obtained through diverse acquisition techniques, in different light conditions, composed of various size and resolution. The difficulty to elaborate, compare, examine and validate these data prior to restauration, leads to the necessity to improve the analyze process. The documentation process has to be expanded in order to help experts to create, enrich and share information about the historical buildings [1]. Change detection is an important analyze method which helps the comprehension of a building. During the process of change detection, an object is observed in subsequent time periods to identify the differences in the surface state of the object and to quantify the chronological effects on the multitemporal data set [2].

Photographs testify the state of preservation of a building at a specific time and constitute therefore an important value for a change detection process. As well with the development of automated image-based-modeling techniques, large sets of images can be spatially oriented, allowing a very precise computation of change measurements. Nowadays the analysis of historical buildings is performed mostly on 3D point clouds, consenting a direct three-dimensional approach [3] but they present as well the difficulty to occupy very large disk space, being composed of a lot of data. Moreover a 3D viewer appears to be problematic to be handled in the field and by non-experts of point cloud processing.

Therefore, it was decided to elaborate here a more end-user friendly approach by using images such as depth maps of ortho images for the chronical change computation. An experimentation was set up by simulating various alteration types on an artificial object and creating a multitemporal data set in order to test this specific method.

\section{ACQUISITION AND DATA PROCESSING}

This approach of change measurement, by using depth maps of the ortho images, is based essentially on a set of tools and procedures concerning the on-going development of an automated image-based 3D reconstruction method [4]. The process consists of an automated calibration and orientation of images, a dense multi-view correlation which leads to an ortho image generation in order to compare the morphological evolution of the deterioration patterns.

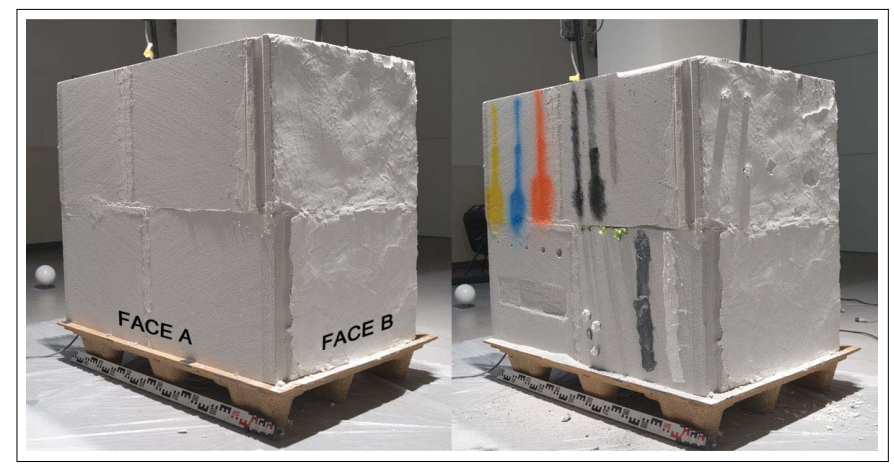

Fig. 1. The wall on which the experiment was carried out in time period T0 (left) and time period T3 (right).

\section{A. Study case}

The experiment was carried out on a small artificial wall with L shape in cellular concrete (ca. $1.50 \times 1.50 \times 0.75 \mathrm{~m}$ ), placed in an environment that allowed to perform different operations that simulate the nearest real conditions for three 
different types of illumination (raking light under tungsten lightening, front illumination with fluorescent light tubes and zenithal illumination with neon colored day light) and many of the degradation patterns according to Vergès-Belmin [5] on stone deterioration.

The several degradation types were performed in four different steps, creating manually the loss and the adding of material within intervals of a few days. In a first state (T0), the wall was intact, in its new original shape, then in a second moment (T1), several types of alterations simulating deteriorations belonging to different families of the reference glossary like detachment, features induced by material loss, discoloration, deposits and biological colonization, were realized by means of some tools (sand paper, chisel, drilling device) and products (paintings, gypsum plaster, black lamp, vegetation). Then followed step three (T2) and four (T3), where each degradation pattern was successively intensified (thickness, depth, superficial expansion, chromatic saturation, etc.) (Fig.1).

\section{B. Acquisitions}

276 photographs were taken in the four different time periods, 23 for each alteration step and illumination condition. The acquisition was carried out with a Nikon D800E with an $\mathrm{f} / 8$ aperture and a focal length of $35 \mathrm{~mm}$, following the acquisition protocol needed for a correct multi-view stereo correlation [6]. The position of the camera didn't have to be exactly the same thanks to the robustness of the orientation tool that was used afterwards. Nevertheless the acquisition positions were chosen quite similar in each phase to allow a more precise confrontation of the different steps and conditions.

In each time period was performed also one scan with a Faro Scan to extract later the Ground Control Points (GCP) information to scale the final orientation.

\section{Automated orientation of images}

The whole set of photographs was computed with the SIFT algorithm, in order to perform the tie point recognition for a matching between the images. The acquisitions of the three different light conditions, which simulate the diachronic impact on illumination (Fig.2) were all calculated together. The SIFT algorithm is robust enough to find descriptors between the different illuminations.

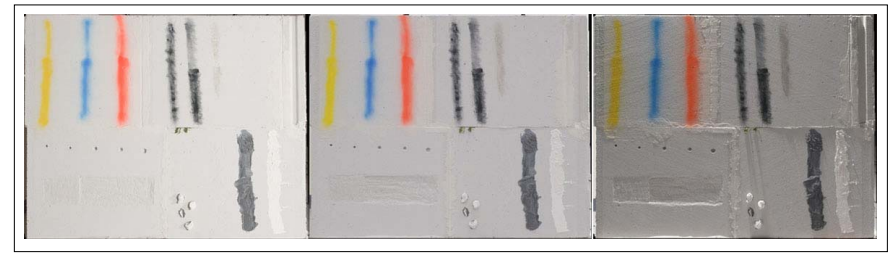

Fig. 2. The three simulations of the diachronic illumination (from left to right): front illumination with fluorescent light tubes (fluo_ldj), zenithal illumination with neon colored day light (fluo_zenital) and raking light under tungsten lightening (halo_rasant).

To optimize the orientation process, the set of photographs was divided into six different groups, one group for each significant correlation (COR) and orientation (ORI) position and a sixth group taking all the pictures at one time period (T2) with a specific light condition (halo rasant) (Fig.3).

\begin{tabular}{|c|c|c|c|c|c|c|}
\hline Time & $\begin{array}{c}\text { Light } \\
\text { condition }\end{array}$ & $\operatorname{COR} A$ & ORI A & COR AB & ORI B & COR B \\
\hline TO & Fluo_Idj & $x$ & $\mathrm{x}$ & $\mathrm{x}$ & $\mathrm{x}$ & $\mathrm{x}$ \\
\hline T0 & Fluo_zenital & $x$ & $x$ & $x$ & $x$ & $x$ \\
\hline TO & Halo_rasant & $x$ & $x$ & $\mathrm{x}$ & $x$ & $\mathrm{x}$ \\
\hline T1 & Fluo_Idj & $\mathrm{x}$ & $\mathrm{x}$ & $\mathrm{x}$ & $\mathrm{x}$ & $\mathrm{x}$ \\
\hline T1 & Fluo_zenital & $x$ & $\mathrm{x}$ & $\mathrm{x}$ & $\mathrm{x}$ & $\mathrm{x}$ \\
\hline T1 & Halo_rasant & $x$ & $x$ & $x$ & $x$ & $x$ \\
\hline $\mathrm{T} 2$ & Fluo_Idj & $\mathrm{x}$ & $x$ & $\mathrm{x}$ & $\mathrm{x}$ & $\mathrm{x}$ \\
\hline $\mathrm{T} 2$ & Fluo_zenital & $\mathrm{x}$ & $\mathrm{x}$ & $\mathrm{x}$ & $\mathrm{x}$ & $\mathrm{x}$ \\
\hline T2 & Halo_rasant & $x$ & $x$ & $x$ & $x$ & $x$ \\
\hline T3 & Fluo_Idj & $x$ & $x$ & $x$ & $x$ & $x$ \\
\hline T3 & Fluo_zenital & $x$ & $\mathrm{x}$ & $x$ & $x$ & $\mathrm{x}$ \\
\hline $\mathrm{T} 3$ & Halo_rasant & $\mathrm{x}$ & $\mathrm{x}$ & $x$ & $\mathrm{x}$ & $\mathrm{x}$ \\
\hline
\end{tabular}

Fig. 3. The six orientation groups divided by acquisition positions, time periods and light conditions.

For the second processing step, the recognition of the camera's geometric model internal parameters, a camera calibration was used, which had been created previously through a calibration performed on a test set.

The final image orientation was computed automatically adding one by one all the images and proceeding a bundle adjustment to refine each image orientation (Fig.4).

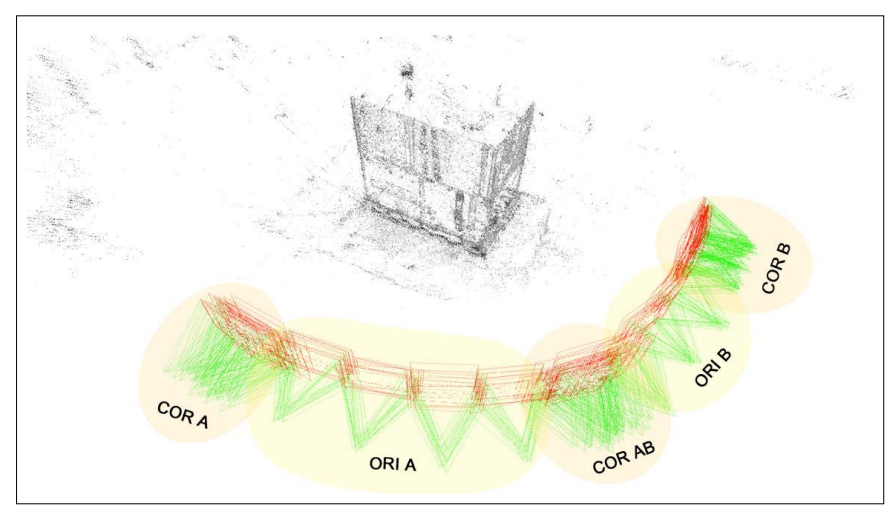

Fig. 4. SIFT points and image orientation

To scale the set of photographs in correspondence to the acquired point clouds from the laser scanner, significant points were chosen on the scan point cloud and their GCP information was transferred into the image processing project. The image orientation was recalculated at this point creating a new global transformation of the orientation.

\section{Creation of ortho images and depth maps}

Now that the images were oriented in relation with each other, ortho images of each face of the wall and of each time period and light condition could be generated. Ortho images are the best approach for a comparison since they give a plane for the reference geometry. The points which have to be compared, get projected by the least mean square method on a plane, which can be used then to produce as well the depth maps, which show the distances of each point to this reference plane.

Therefore an adjacent plane was created on each face of the wall by drawing a mask on the pictures of face $\mathrm{A}$ and $\mathrm{a}$ mask on face B. The reference system could be recalculated 
according to the recognized tie points belonging to the mask and the adjacent midplane was computed with the least square fitting estimation.

A first collage of the interested photographs was obtained where it was possible do draw a mask on each result of each face of the wall to indicate which part of the scene should be used for the following ortho image creation. The final ortho image was computed by a dense matching-base surface reconstruction automatic method [7-8], that generates, on each relevant image, a depth map, a mask and an ortho image. These data were merged together by computing for each individual ortho image a radiometric equalization using the least mean square, generating the final ortho image.

In addition to this final ortho image, also a 16 bits depth map image of each ortho image was created. These depth map images of the different time periods were used for the following change measurement process. (Fig.5).

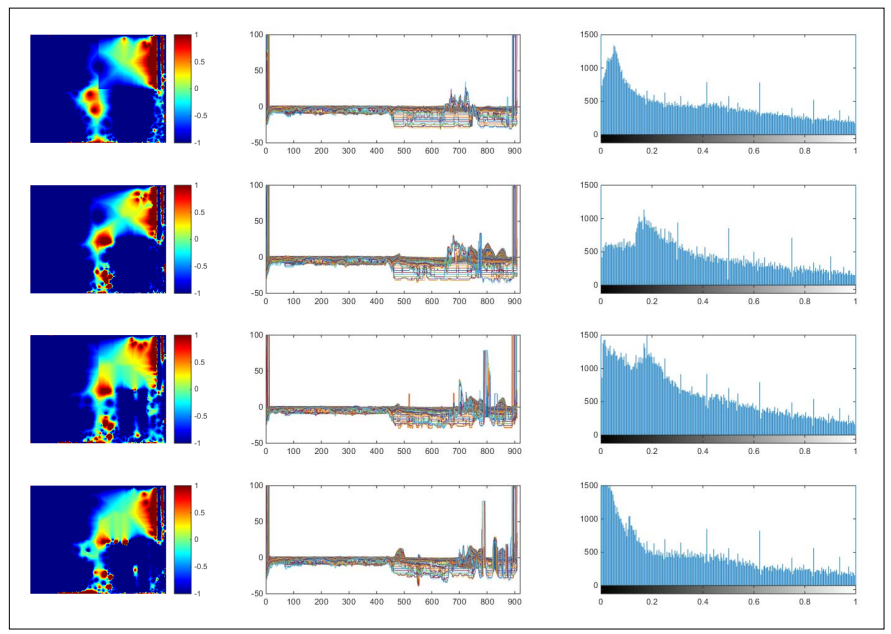

Fig. 5. The four depth maps of time period T0, T1, T2 and T3 of face A and their histograms.

\section{CHANGE MEASUREMENTS}

Once the oriented depth maps of the different time periods were generated, the process of change measurement could be set up. An approach was chosen to simply compute an image differencing between the spatially registered depth maps of the various time periods. By computing an image difference, a further image is produced that represents the variation between the two different times.

A numeric computation software can read the 16 bit depth images as matrixes and compute the distance of each $\mathrm{z}$-value of the depth map. The matrixes representing the spatially oriented depth maps of two ortho images of two time periods are subtracted, generating a new matrix which describes the modifications and can be visualized in form of an image of change quantification. (Fig.6).

The two main problems that can appear while computing the change quantifications on the various depth maps, are when the different images are not oriented spatially on the same plane and are not identical in size and resolution.
The orientation problem was resolved in this specific approach thanks to the generation of the adjacent midplane on each face of the wall in the previous elaboration phase when the ortho images were generated. The same midplane was used for the generation of each ortho image of each time period and therefore the resulting depth maps of each ortho image were spatially oriented in the same reference system and had the same coordinates.

The size problem was fixed during the same step of this workflow, when a mask was drawn on the collage of the interested photographs prior to the creation of the final ortho image. The same mask was used for the generation of each ortho image of each time and therefore the same part of the pictures was taken in consideration, generating images of the same size.

Nevertheless the depth maps appeared to be composed by various resolutions. After having computed a resize of the resolution of the depth map images in order to obtain four depth images of the same size and resolution, it was possible to visualize a change quantification, computing the $\mathrm{z}$-distance differences between each image. With the help of colors are visualized the differences computed, caused by added and subtracted material (Fig.7).

A critical element of the image differencing method is deciding where to place the threshold boundaries between change and no-change pixel displayed in the histogram which has to be evaluated probably for each specific survey case and depending on the precision with whom the differences want to be recognized. In this case the boundaries were set in an interval of $10 \mathrm{~cm}$ to show the adding and loss of material with a high precision expressed in a multicolored map.

Analyzing the outcomes of the different light conditions, it results that the restitution of the acquisitions made during the tungsten raking light illumination showed less noise in comparison to the others. However the SIFT algorithm used, was able to perform a robust bundle adjustment with each different light condition for the orientation of the images.

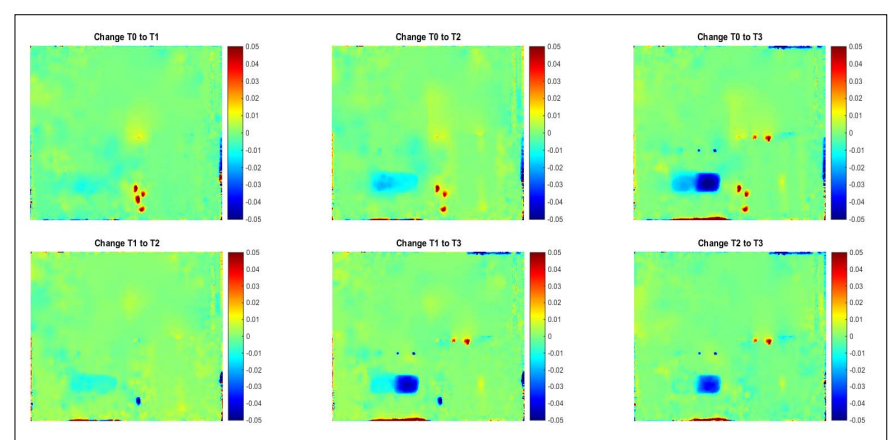

Fig. 6. The various changes between the different time periods: in the first row are visible the changes going from $\mathrm{T} 0$ to $\mathrm{T} 1, \mathrm{~T} 0$ to $\mathrm{T} 2$ and $\mathrm{T} 0$ to $\mathrm{T} 3$. In the second row are visible the intermediary changes going from time period $\mathrm{T} 1$ to $\mathrm{T} 2, \mathrm{~T} 1$ to $\mathrm{T} 3$ and $\mathrm{T} 2$ to $\mathrm{T} 3$.

\section{CONCLUSION}

The procedure for a change measurement described in this work is the first approach of a new elaboration of a complete process of quantitative change monitoring on a multitemporal 


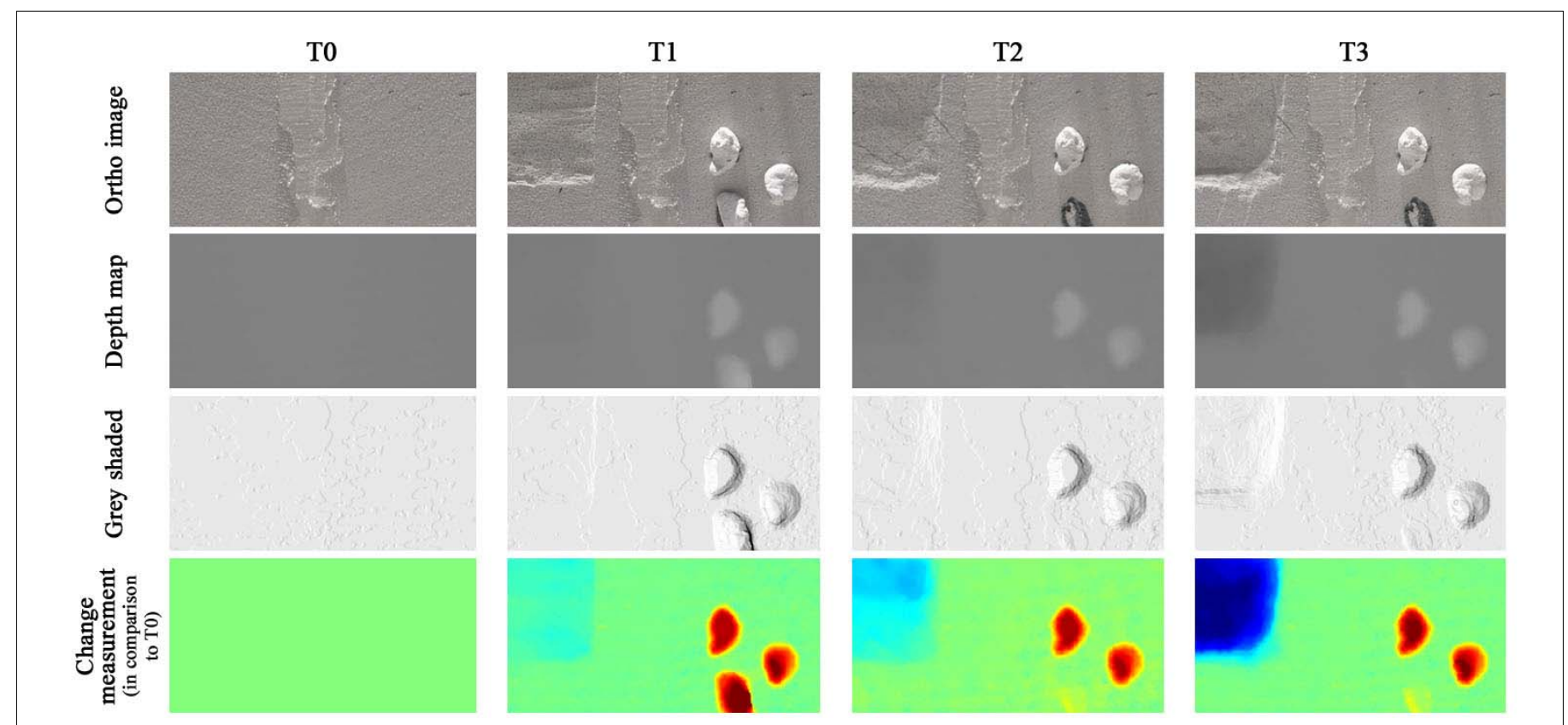

Fig. 8. The change computation in detail: the first row shows parts of the ortho images in the four different states of deterioration, the second and third row show the depth maps and the corresponding grey shaded images, while the fourth row shows the images of change measurement of each time period in correspondence to $\mathrm{T} 0$.

data set. It is based on the interpretation of non-threedimensional data, in order to facilitate the storage, the handling and the elaboration of this data and to make it more user-friendly for non-experts of 3D-point cloud processing. Therefore the complete process is not finished here and much work remains, but some applications can be already considered by using this first approach. The conservation of historic buildings and archeological excavations could be monitored with this method, quantifying the dimensional changes during various time periods.

The experiment conducted here will be enriched with the addition of a chromatic change measurement by elaborating an approach using the ortho images even of the different light simulations, to be able to monitor not only the dimensional alterations and degradations but also the chromatic deterioration patterns.

Furthermore the approach by now validates the geometric point of view, but future informatics implementations will require more in-depth analysis of several issues, that have to be taken into account for the ongoing development.

A future challenge will be also to carry out the process of change measurement on a multitemporal data set of an actual building where the alterations and degradations are unknown in order to test the efficiency of this approach.

The aim will be to monitor quantitatively the evolution of the deterioration patterns in different resolutions, starting from images that were taken from various points of view, with different expositions and in dissimilar time periods. Computing the development of the deterioration patterns will be of great interest for conservations, starting from the diagnose procedures to the following elaborations that will be applied during the restauration process.

\section{ACKNOWLEDGMENT}

We would like to thank Sébastien Aze for supplying the materials and building the experimental wall.

\section{REFERENCES}

[1] A. Manuel, E. Gattet, L. De Luca, An approach for precise 2D/3D semantic annotation of spatially-oriented images for in situ visualization applications, Proceedings of the 2013 Digital Heritage International Congress, Volume 1, Marseille, France, 28 Oct-1 Nov 2013

[2] A. Singh, Digital change detection techniques using remotelysensed data, International Journal of Remote Sensing, 1989

[3] D. Girardeau-Montaut, Détection de changement sur des données géometriques tridimensionelles, Télécom ParisTech, 2006

[4] MicMac, Apero, Pastis and Other Beverages in a Nutshell! Tutorial, December 26, 2014

[5] V. Vergès-Belmin (ed.), Illustrated glossary on stone deterioration patterns, ICOMOS International Scientific Committee for Monuments and Sites, 2008.

[6] Martin-Beaumont, N., Nony, N., Deshayes, B., PierrotDeseilligny, M. and De Luca, L., 2013. Photographer-friendly work-flows for image-based modeling of heritage artefacts. In: ISPRS - International Archives of the Photogrammetry, Remote Sensing and Spatial Information Sciences, XL-5/W2 (July 22, 2013): 421-424.

[7] M. Pierrot-Desseiligny and I. Cléry, Apero, an open source bundle adjustment software for automatic calibration and orientation of a set of images, Proceedings of the ISPRS Commission V Symposium, Image Engineering and Vision Metrology, Trento, Italy, 2-4 March 2011

[8] M. Pierrot-Desseiligny, L. De Luca and F. Remondino, Automated image-based procedures for accurate artifacts 3D modeling and orthoimage generation, Geoinformatics FCE CTU Journal, vol. 6, pp. 291-299, Prague, Czech Republic, 2011 